\title{
SAFETY IN HANDLING OF CADAVERS
}

\section{KARTHIKA JAYAKUMAR AND SWAYUM JOTHI}

Sri Sathya Sai Medical College \& Research Institute, Ammapet, Kanchipuram- 603108, TN, India.

*Corresponding Author: Email- jayakumarkarthika900@gmail.com.

\begin{abstract}
-
Aim: To know the presence/ absence of infectious agents like:

Bacterial Causes: Tuberculosis, Gram positive \& Gram negative organisms.

Viral Causes: HEPATITIS B\&C; HIV in cadavers.

Materials \& Methods: Samples were collected from 6 medical colleges in and around Tamil Nadu\& Andhra Pradesh. A total of 28 cadavers were screened, 3 samples from each body were taken which includes fluid from cranial cavity, thoracic cavity, abdominal cavity, totally constituting 84 samples. The samples were processed for both bacterial and viral etiological agents as per standard lab protocols. Results: All the 84 samples were negative for bacterial agents but 2 cadavers proved to be positive for viral infectious diseases revealing the necessity to screen the samples from the cadavers before it is handed over to the Anatomy dissection hall, to be handled by the teachers and the taught. One cadaver was positive for HIV and another cadaver positive for Hepatitis B infection in all the three samples. Conclusions: The safety of embalmed cadaver was unquestioned till date as it was thought to be infection free!! Our study proved otherwise

All the samples were devoid of bacterial infections but two cadavers proved to be positive for viral infections, stressing the importance of screening the cadavers for bacterial \& viral infections.

Universal precautions are to be followed wherever necessary along with vaccination.
\end{abstract}

Key words- Cadavers, Bacterial Causes, Viral Causes,

Citation: Karthika Jayakumar and Swayum Jothi (2012) Safety in Handling of Cadavers. International Journal of Medical and Clinical Research, ISSN:0976-5530 \& E-ISSN:0976-5549, Volume 3, Issue 3, pp.-140-142.

Copyright: Copyright@2012 Karthika Jayakumar and Swayum Jothi . This is an open-access article distributed under the terms of the Creative Commons Attribution License, which permits unrestricted use, distribution, and reproduction in any medium, provided the original author and source are credited.

\section{Introduction}

In recent years, there has been a growing realization that a sound knowledge of gross anatomy is so very essential for a surgeon which is similar to a motor mechanic knowing the working parts of an internal combustion engine.

It is also vital for a medical student to have a thorough knowledge about the dissected body to have a strong foundation on which his future career will be launched.

In this regard, the epidemiology of infectious diseases from a clinically silent zone like Anatomy involving the safety in handling of cadavers becomes an essential \& important data to be analyzed; therefore we undertook this study in our college to detect the presence/ absence of infectious diseases in cadaver. To know the presence/ absence of infectious agents like:

- Bacterial Causes: Tuberculosis, Gram positive \& Gram negative organisms.

- Viral Causes: HEPATITIS B\&C; HIV in cadavers[3].

And thereby making it safe to be handled by the mortuary \& anatomy dissection hall workers along with Anatomy teachers \& students.

To implement universal precautions to prevent the spread of the infection and also to motivate the paramedical personnel to have vaccination as a prophylactic measure 


\section{Subjects and Methods}

Study Peroid: April 2011-August 2011(Five months).

Inclusion Criteria: Bodies which were received in the Anatomy department within six months of embalming \& the death resulting from natural causes.

Exclusion Criteria: Extremities of age, mutilated bodies due to accidents and other unnatural cause of death.

Samples were collected from 6 medical colleges in around Tamil Nadu \& Andhra Pradesh.

A total of 28 cadavers were screened, 3 samples from each body were taken: 1) cranial cavity fluid, (2) thoracic cavity fluid, (3) abdominal cavity fluid.

The samples were collected aseptically and transported in a sterile container to the microbiology lab along with the patient details like sex, age and cause of death.

We had a total of 84 samples during the five month period. These samples were subjected for bacterial and viral screening procedures. The samples were subjected for Gram's \& AFB staining techniques as per standard protocol [5].

The supernatant \& centrifuged deposit of the sample was inoculated into Mac-Conkey agar, blood agar \& chocolate agar

The plates were inoculated in two sets: one aerobic \& the anaerobic incubation as per lab standard [4]. The plates were incubated for $48 \mathrm{hrs}$ and reported negative if found sterile.

The specimen was inoculated in LJ medium and incubated for 6- 8 weeks. The media was inspected for colony growth after 3 days of incubation to rule out the presence of rapid grower's ,then further incubated up to 6 weeks, if there was no growth, it was reported as negative for Tuberculosis infection [5].

The specimen were also screened for the presence of viral infections like: HIV, HEPATITIS B\&C, by performing ELISA by the conventional methods[6].

\section{Results}

Out of the 28 cadavers: 20 were male, 8 were female having a sex distribution of $5: 2$.

The age group ranged from 20-60years. The cause of death was: Renal failure complicating diabetes (55\%), Myocardial infarction (29\%), Septicaemia (11\%) \& unknown cause (5\%) (Chart 1).

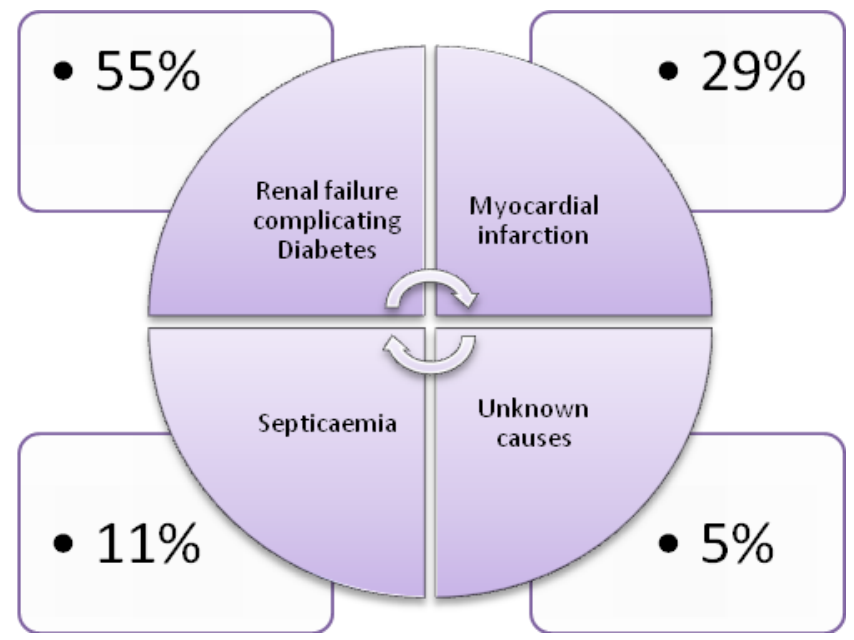

Chart 1- Distribution of causes of death
All the 84 samples were negative for bacterial infectious diseases, but 2 samples were found to be positive, one for HIV infection \& another for Hepatitis B infection with all the three samples.

This was an unexpected result as there were no positive reports recorded in the cadavers in India. Therefore cadavers were considered to be safe for handling by the teachers \& the taught!! But our study has disproved this concept, by having a positive report for both HIV (Figure2, 3 \& 4) \& HEPATITIS B (Figure1) which makes the screening of the cadavers \& its samples mandatory.

This study was undertaken to prove the safe handling of the cadaver in the field of medicine and also to detect the presence/ absence of the diseases like HIV \& tuberculosis in the dead body.

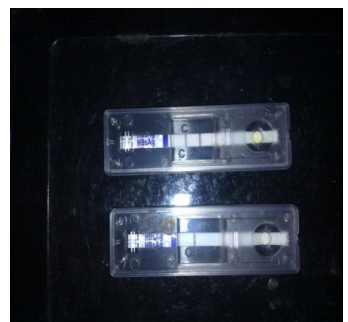

Fig. 1- HBsAg

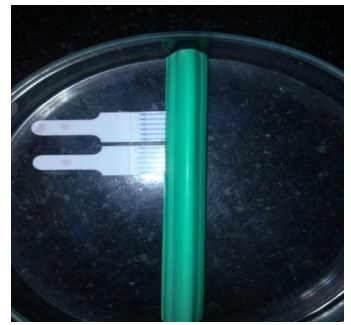

Fig. 3- Immuno comb test for HIV

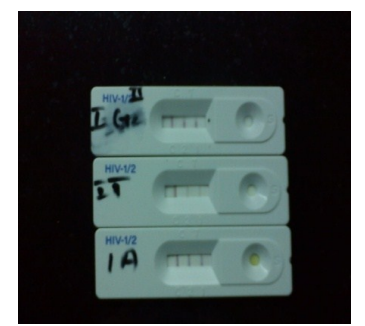

Fig. 2- HIV-1/2

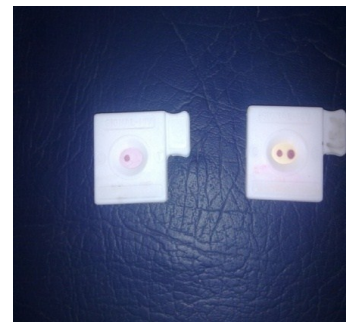

Fig. 4- Tri-dot HIV1/2

\section{Discussion}

The epidemiology of infectious disease in clinical studies is a wellknown entity but in a clinically silent zone like Anatomy the studies on cadavers are underestimated. So this study was undertaken by us to prove the safety of cadavers in teaching and research activities. In our study it was $100 \%$ negative for bacterial and $93 \%$ negative for viral infections-ONE HIV POSITIVE \& ANOTHER HEPATITIS B POSITIVE.

Yet another validating point to procure this study was: Tuberculosis DNA can be detected even in mummies which dates to $1550-$ 1080BC[7], HIV can persist up to 16 days after death[8].

\section{Conclusions}

Our study was the first of its kind in INDIA.

All the samples were devoid of any bacterial, but $7 \%$ had viral infections, proving the importance of screening of cadavers before handling.

If any infection found positive, the cadaver handler has to be advised to follow the universal barrier precautions: wearing apron, use of gloves and proper disposal of the used gloves, mask\& apron whenever there is a splash of fluids [9].

In any given situation it is ideal to get vaccinated as it is better to prevent than to cure [10]. 


\section{References}

[1] Subhash Chandra Parija. Text book of Microbiology and Immunology, 2nd Edition, 591.

[2] Ananthanarayan and Paniker's. Text book of Micro-Biology 8th Edition, 356.

[3] Tolhurst D.E. and Hart J. (1990) Eur. J. Plast. Surg., 13, 7578.

[4] Washington Winn, Jr. et al Koneman's Color Atlas and Test book of Diagnostic Microbiology, 6th Edition.

[5] Collee J.G., Fraser A.G., Marmion B.P., Simmons A. Mackie \& McCartney Practical Medical Microbiology, 14th edition, 858859.

[6] Oliver Morgan (2004) Infections disease risks from dead bodies following natural disasters, 15(5), 307-12.

[7] Rana F.S., Hawken M.P. (2000) Journal of Acquired Immune Deficiency Syndromes, 24(1), 23-29.

[8] Betty A. Forbes et.al., Bailey and Scott's Diagnostic Microbiology, 12th Edition. 950-951.

[9] Cattaneo C., Nuttall P.A., Molendini L.O. (1999) J. Clin. Pathol., 52, 267-270.

[10]Dirk De Craemer (1994) N. Engl. J. Med., 331, 1315.

[11]Park's Test book of preventive and Social Medicine, 744. 